\title{
Vitrectomy for laser-induced full-thickness macular hole
}

\author{
Xin Wang ${ }^{1 \dagger}$, Ting Zhang ${ }^{1 \dagger}$, Rui Jiang ${ }^{1 *}$ and Gezhi $X u^{1,2,3}$
}

\begin{abstract}
Background: To report the structure and visual outcomes of pars plana vitrectomy (PPV) for laser-induced fullthickness macular holes (MHs).

Methods: This retrospective study enrolled 10 patients who underwent vitrectomy for MHs caused by laser injury. Best corrected visual acuity (BCVA), macular spectral-domain optical coherence tomography (OCT) and OCT angiography (OCTA) were used for assessment.

Results: Four patients were injured by unexpected expose of an yttrium aluminum garnet (YAG) laser, and six patients were accidentally injured by a handheld laser. The MH minimum diameters (MDs) ranged from 55 to $966 \mu \mathrm{m}$ (mean $=548.00 \pm 286.10 \mu \mathrm{m})$, and BCVA ranged from 20/400 to 20/50 (mean $=\log M A R \quad 0.87 \pm 0.29)$ preoperatively. All 10 eyes underwent PPV, internal limiting membrane (ILM) peeling, and gas tamponade. All eyes demonstrated closure of the $\mathrm{MH}$ with different degrees of discontinuity of the outer layer of the retina, and four eyes exhibited serious retinal pigment epithelium (RPE) destruction. Postoperative BCVA values were significantly improved (mean $=\log M A R 0.55 \pm 0.33 ; P=0.032, t=2.234$ ). The mean BCVA of the destroyed RPE group was significantly worse than that of the non-destroyed RPE group both before and after surgery $(P=0.019$; Wilcoxon signed rank test). Further, OCTA indicated choroidal ischemia in the laser-induced MHs.
\end{abstract}

Conclusion: Vitrectomy can be successful in closing laser-induced full-thickness MHs and improving visual acuity. However, If RPE/choroid is involved in laser damage in addition to the outer retinal layer, this may indicate poor visual prognosis.

Keywords: Laser injury, Macular hole, Vitrectomy, Optical coherence tomography, Optical coherence tomography angiography

\section{Background}

Reports of laser-induced macular holes (MHs), a special subtype of secondary MHs, have increased in recent years [1-3]. A careful review of medical history is essential for the correct clinical diagnosis. The type of laser can be neodymiumdoped yttrium aluminum garnet (Nd:YAG) or handheld lasers. Pars plana vitrectomy (PPV) has been used for the treatment of this condition

\footnotetext{
* Correspondence: academicxw@163.com

${ }^{+}$Xin Wang and Ting Zhang contributed equally to this work.

${ }^{1}$ Eye Institute and Department of Ophthalmology Vision Sciences, Eye \& ENT Hospital, Fudan University, 83 Fenyang Road, Shanghai 200031, China Full list of author information is available at the end of the article
}

in a few previous reports, but the number of such cases has remained small and the outcomes of this treatment have varied [4-7]. Herein, we collected 10 eyes of 10 patients who underwent vitrectomy for laser-induced MHs at the Eye and ENT Hospital of Fudan University to observe their structure and visual outcomes.

\section{Material and methods}

This retrospective, observational study involved 10 patients treated by vitrectomy for full-thickness MHs caused by laser in the Eye Institute and Department of Ophthalmology at the Eye and ENT Hospital of Fudan University, China from 2013 to June 2018. This study

C C The Author(s). 2021 Open Access This article is licensed under a Creative Commons Attribution 4.0 International License, which permits use, sharing, adaptation, distribution and reproduction in any medium or format, as long as you give appropriate credit to the original author(s) and the source, provide a link to the Creative Commons licence, and indicate if changes were made. The images or other third party material in this article are included in the article's Creative Commons licence, unless indicated otherwise in a credit line to the material. If material is not included in the article's Creative Commons licence and your intended use is not permitted by statutory regulation or exceeds the permitted use, you will need to obtain permission directly from the copyright holder. To view a copy of this licence, visit http://creativecommons.org/licenses/by/4.0/ The Creative Commons Public Domain Dedication waiver (http://creativecommons.org/publicdomain/zero/1.0/) applies to the data made available in this article, unless otherwise stated in a credit line to the data. 
was approved by the Medical Ethical Committee of the Eye and ENT Hospital of Fudan University. Each patient or his/her legal representative signed the informed consent to render treatment prior to surgery. The initial and follow-up evaluations included Snellen best corrected visual acuity (BCVA) measurement, slit-lamp biomicroscopy, spectral-domain optical coherence tomography (SD-OCT) (Spectralis OCT; Heidelberg Engineering, Heidelberg, Germany, or Cirrus; Carl Zeiss Meditec, Inc., Dublin, CA, USA), and PLEX Elite 9000 swept source OCT angiography (OCTA, Carl Zeiss Meditec, Inc., Dublin, CA, USA). The minimum linear diameter of the $\mathrm{MH}$ in horizonal OCT scans was defined as minimum diameter (MD). The base diameter (BD) was measured at the level of the retinal pigment epithelium crossing the center of the MH. Serious RPE destruction or destroyed RPE was defined the RPE layer under MH disappeared or couldn't been recognized completely in SD-OCT.

All patients were treated by standard 23-gauge PPV combined with indocyanine green-assisted internal limiting membrane (ILM) peeling, and fluid-air exchange or inert gas (SF6 or C3F8) tamponade by multiple doctors. Among them, inverted ILM flap [8] technique was used in patient 1, 3, 4 and 9. The choice of tamponade was made depending on each doctor's preference and the availability of tamponade. The patients remained prone for at least 5 days following surgery.

Data were analyzed using statistical software (SPSS version 18, IBM-SPSS, Chicago, IL, USA). Snellen BCVA value was converted to the logarithm of the minimal angle of resolution (logMAR) for the purpose of statistical analysis. Preoperative and postoperative visual acuities were compared using a paired Student's t-test or a Wilcoxon signed rank test. The correlations of preoperative BCVA and $\mathrm{MH}$ size with postoperative
BCVA were analyzed using Spearman's correlation. A $P$-value $<0.05$ was considered statistically significant.

\section{Results}

The present study involved 10 eyes of 10 patients with full-thickness MHs (Table 1). This sample included two females and eight males, and the mean age was $23.30 \pm$ 7.87 years (range: 13-39 years). Six patients (P1-P6) were injured by unexpected expose of handheld lasers when playing laser points by themselves or by others, and four patients (P7-P10) were injured by unexpected expose of YAG lasers when modulating the YAG laser transmitter in occupational settings. The mean interval from injury to surgery was $4.08 \pm 3.6$ months, and the mean follow-up time was $13.03 \pm 18.06$ months. The mean preoperative BCVA value was $\log$ MAR $0.86 \pm 0.31$ (range: $20 / 400$ to $20 / 50$ ). The mean preoperative MD and $\mathrm{BD}$ were $548.00 \pm 286.10 \mu \mathrm{m}$ and $1196.40 \pm$ $524.41 \mu \mathrm{m}$, respectively.

After 23-gauge PPV combined with ILM peeling, and gas tamponade (air, SF6, or C3F8), all 10 treated eyes (100\%) showed MH closure at the last follow-up after operation (Fig. 1). The mean BCVA improved from logMAR $0.87 \pm 0.29$ (range: $\log$ MAR $0.3-1.3$ ) to $\log$ MAR $0.55 \pm 0.33$ (range: $\operatorname{logMAR} 0.1-1.0 ; P=0.032, \mathrm{t}=2.234$ ) (Fig. 2a). Postoperative BCVA was significantly correlated with preoperative BCVA $(P=0.000$, Spearman's coefficient $=0.953$ ) but was not correlated with $\mathrm{MD}$ or BD $(P=0.191$, Spearman's coefficient $=0.451$; and $P=0.054$, Spearman's coefficient $=0.624$, respectively). In P2, P5 and P8, external limiting membrane (ELM) became continuous after surgery. Postoperative BCVA was also significantly correlated with integrity of ELM after surgery $(P=0.039$, Spearman's coefficient $=-0.658)$.

Table 1 Clinical characteristics of patients with full-thickness MH caused by laser

\begin{tabular}{|c|c|c|c|c|c|c|c|c|c|c|}
\hline Patient No. & Age & Sex & $\begin{array}{l}\text { Laser } \\
\text { type }\end{array}$ & $\begin{array}{l}\text { Interval From } \\
\text { Injury to Sugery }\end{array}$ & $\begin{array}{l}\text { Preoperative } \\
\text { BCVA }\end{array}$ & $\begin{array}{l}\text { Tamponade } \\
\text { agent used }\end{array}$ & $\begin{array}{l}\text { MH Size } \\
(\mathrm{MD} / \mathrm{BD}) \\
(\mu \mathrm{m})\end{array}$ & $\begin{array}{l}\text { Last follow-up } \\
\text { After PPV } \\
\text { (months) }\end{array}$ & $\begin{array}{l}\text { BCVA } \\
\text { at last } \\
\text { follow-up }\end{array}$ & $\begin{array}{l}\text { Post } \\
\text { operative } \\
\text { OCT }\end{array}$ \\
\hline $1^{*}$ & 39 & $M$ & laserpoint & $2 \mathrm{mo}$ & $20 / 200$ & Air & $606 / 1042$ & $5 w k$ & $20 / 100$ & Closed \\
\hline 2 & 16 & M & laserpoint & $6 \mathrm{mo}$ & $20 / 100$ & Air & $358 / 982$ & $11 \mathrm{mo}$ & $20 / 67$ & Closed; \\
\hline $3^{*}$ & 17 & $\mathrm{~F}$ & laserpoint & $1 \mathrm{mo}$ & $20 / 167$ & Air & $601 / 969$ & $13 \mathrm{mo}$ & $20 / 50$ & Closed; \\
\hline $4^{*}$ & 25 & $\mathrm{~F}$ & laserpoint & $2 \mathrm{mo}$ & $20 / 250$ & Air & $966 / 2255$ & $6 \mathrm{mo}$ & $20 / 200$ & Closed; destroyed RPE \\
\hline 5 & 23 & $M$ & Laserpoint & $12 \mathrm{mo}$ & $20 / 50$ & C3F8 & $55 / 826$ & $2 \mathrm{mo}$ & $20 / 25$ & Closed \\
\hline 6 & 13 & $M$ & laserpoint & $4 \mathrm{mo}$ & $20 / 167$ & C3F8 & $857 / 2020$ & $2 \mathrm{mo}$ & $20 / 40$ & Closed \\
\hline 7 & 25 & M & Nd:YAG & $3 w k$ & $20 / 200$ & Air & $823 / 1228$ & $1 \mathrm{mo}$ & 20/100 & Closed; destroyed RPE \\
\hline 8 & 22 & M & Nd:YAG & $3 \mathrm{mo}$ & $20 / 40$ & Air & $294 / 602$ & $3 \mathrm{mo}$ & $20 / 25$ & Closed; \\
\hline $9^{*}$ & 33 & M & $\mathrm{Nd}: Y A G$ & $2 \mathrm{mo}$ & $20 / 200$ & C3F8 & $573 / 1041$ & $54 \mathrm{mo}$ & $20 / 100$ & Closed; destroyed RPE \\
\hline 10 & 20 & M & $\mathrm{Nd}: Y A G$ & $8 \mathrm{mo}$ & $20 / 400$ & SF6 & $347 / 999$ & $37 \mathrm{mo}$ & $20 / 200$ & Closed; destroyed RPE \\
\hline
\end{tabular}

Abbreviations: $M H$ macular hole, $M$ Male, $F$ female, $B C V A$ Snellen best-corrected visual acuity, C3F8 perfluoropropane, SF6 sulfur hexafluoride, $M D$ minimum diameter, $B D$ base diameter, $P P V$ pars plana vitrectomy, OCT optical coherence tomography;

*Inverted ILM flap technique was used 


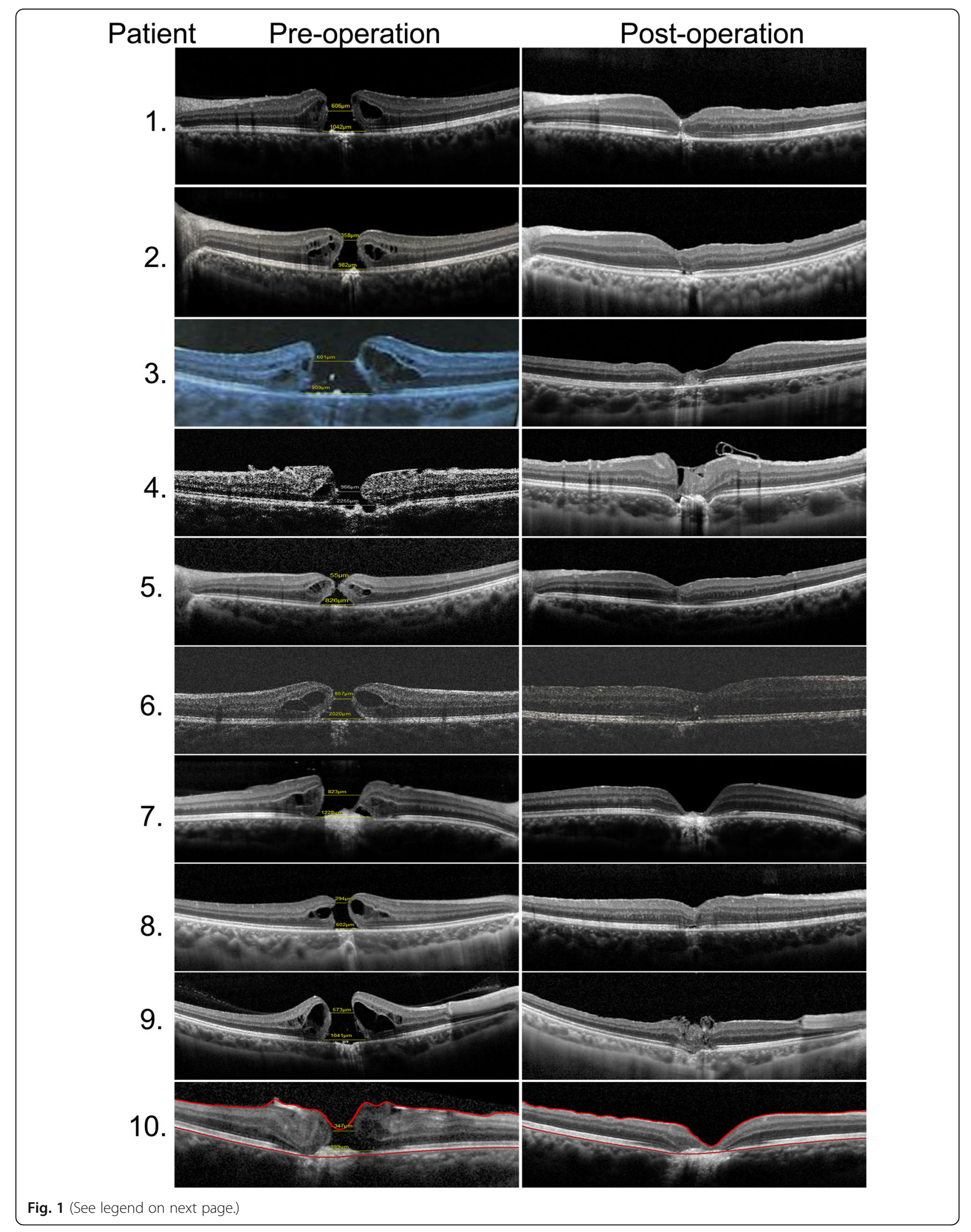


(See figure on previous page.)

Fig. 1 The macular structures of the 10 eyes before (left) and after (right) vitrectomy as shown by SD-OCT. Inverted ILM flap technique was used in P1, 3, 4 and 9. (Left) Ten patients exhibited full-thickness MHs preoperatively. Four patients (P4, P7, P9, and P10) exhibited obvious RPE disruption. (Right) In the three patients (P2, P5, and P8), ELM became continuous after surgery. At the last follow-up, all 10 eyes showed MH closure with various degrees of outer retina defects; four of these patients (P4, P7, P9, and P10) exhibited serious RPE destruction

Various degrees of outer retina defects were seen in all the eyes, of which four patients (P4, P7, P9, and P10) exhibited serious RPE destruction to the degree that the RPE layer could not be seen in SD-OCT. We divided all the patients into two groups: a destroyed RPE (D-RPE) group (P4, P7, P9, and P10) and a non-destroyed RPE (ND-RPE) group (P1, P2, P3, P5, P6, and P8). The mean preoperative BCVA values were logMAR $1.10 \pm 0.14$ and $0.71 \pm 0.30$ in the D-RPE and ND-RPE groups, respectively. The mean postoperative BCVA values were logMAR $0.85 \pm 0.17$ and $0.35 \pm 0.24$ in the D-RPE and ND-RPE groups, respectively. The mean BCVA of the former group was significantly worse than that of the latter group both before and after surgery $(P=0.019$; Wilcoxon signed rank test) (Fig. 2b). Neither the mean $\mathrm{BD}$ or the MD between the D-RPE and ND-RPE groups had significant difference $(P=0.394 ; P=0.163$, respectively, Wilcoxon signed rank test). Furthermore, Both pre- and post-operative BCVA has a significant correlation with RPE destruction $(P=0.006$, Spearman's coefficient $=0.794)$.

Through OCTA, we demonstrated choroidal ischemia caused by laser injury in Patients 2, 3, and 9.The areas of flow deficit demonstrated in the rectangular circle showed choroidal ischemia in P2 (left eye), P3 (right eye), and P9 (right eye) in comparison to their fellow eyes (Fig. 3), which indicated that the depth of laser damage to the eye was capable of reaching the choroid.

\section{Discussion}

The results demonstrated that laser-induced $\mathrm{MH}$ responded well to vitrectomy,

with anatomic closure of the macular hole and improvement of visual acuity, though various degrees of outer retina defects remained. In addition, RPE and choroid damage might indicate poor visual outcomes.

Due to its thermal (e.g., laser pointer) and mechanical (e.g., Nd:YAG laser) effects on the retina, [9, 10] laser treatment can cause various forms of maculopathy, such as subretinal hemorrhage, outer retinal disruption, and full-thickness MHs [11-14].

Some studies have reported vitrectomy for laserinduced MHs [4-7, 15]; of these studies, only those by Alsulaiman and Qi have reported more than five cases of MHs. In Alsulaiman's study, all MHs were caused by a handheld blue laser. And this study showed that 11 of the 14 treated eyes $(78.6 \%)$ exhibited closure of the $\mathrm{MH}$ at the final follow-up; following closure of the $\mathrm{MH}, 8$ of the 11 eyes showed different degrees of discontinuity of the outer layer of the retina [4]. In Qi's study, MHs of five and six patients were caused by an Nd:YAG laser and handheld lasers respectively. All 11 operated eyes (100\%) in Qi's study showed MH closure at the last follow-up after operation, but variable degrees of loss of outer layer of the retina remained, and even part of choroidal defect occurred in four patients in OCT [5].
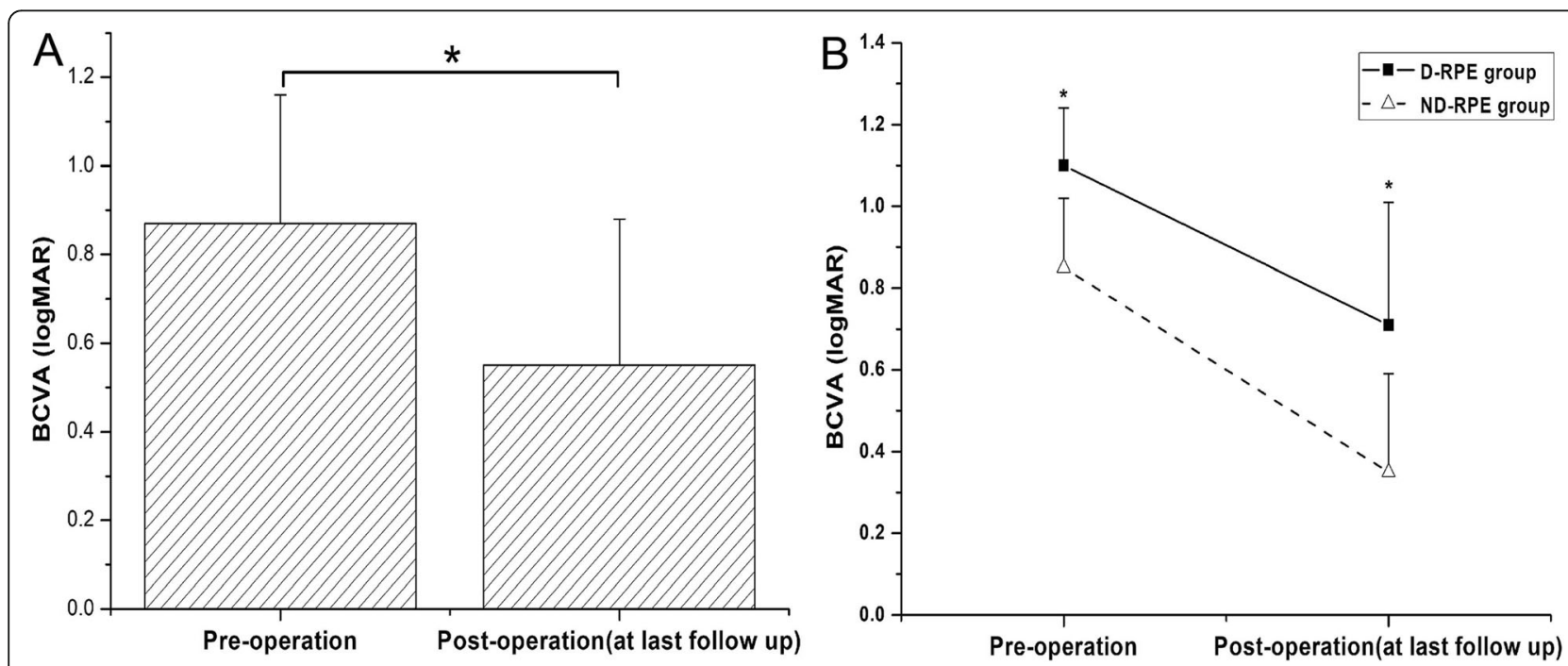

Fig. 2 Changes of visual acuity before and after operation. The mean BCVA significantly improved after surgery at last follow-up in patients $(P=0.032$; t-test) (a). The mean BCVA of D-RPE group was significantly worse than that of the ND-RPE group both before and after surgery $(P=0.019$; Wilcoxon signed rank test). BCVA, Snellen best corrected visual acuity; D-RPE, destroyed RPE; ND-RPE, non-destroyed RPE. ${ }^{*} P<0.05$ between the two groups 


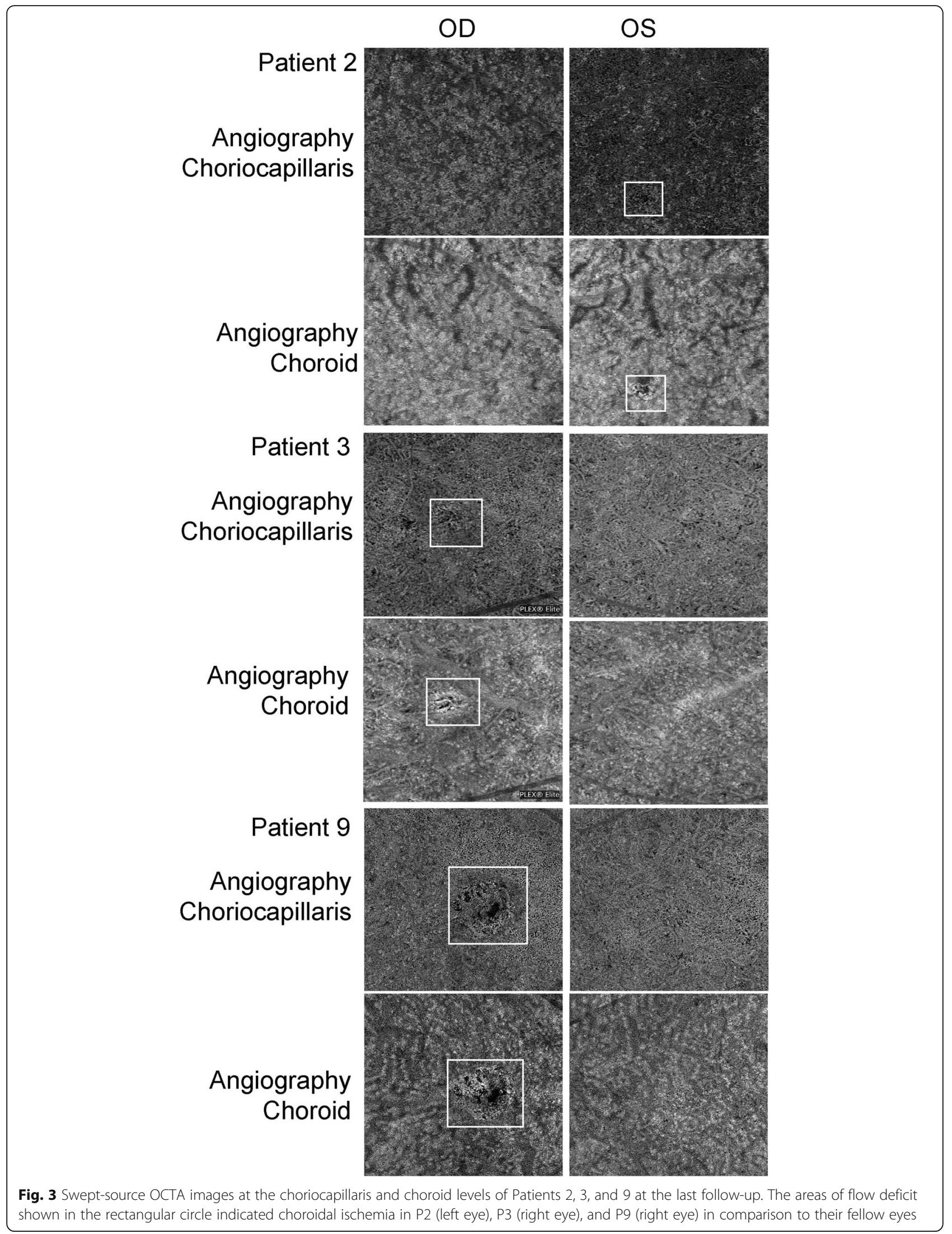


All 10 eyes (100\%) in the present study showed closure of the $\mathrm{MH}$ with variable degrees disruption of outer layer of retina after surgery. The mean MD of $\mathrm{MH}$ in the present case series was $548.00 \pm$ $286.10 \mu \mathrm{m}$, larger than those of Alsulaiman's (351 \pm $151.7 \mu \mathrm{m})$ and Qi's $(505.5 \pm 163.0 \mu \mathrm{m})$ studies. It was worth noting that in four eyes of our cases, the RPE layers were completely unrecognized in OCT, indicating more serious laser damage. Unlike idiopathic MHs, laser-induced MHs could be accompanied by RPE damage and choroidal ischemia. Similarly, RPE disruption has also been reported to accompany $\mathrm{MHs}$ in previous studies [16]. Further, OCTA of the three eyes in our study demonstrated that choroidal ischemia caused by laser injury, indicating the depth of laser damage to the eye, was capable of reaching the choroid level. As far as we knew, there were few reports on OCTA of laser-induced MHs except ours. Similarly, such inner choroidal ischemia demonstrated by OCTA was reported in a case of choroidal neovascularization, but not $\mathrm{MH}$, due to handheld laserinduced maculopathy [17]. OCTA could provide more information about the mechanism of laser-induced $\mathrm{MH}$, and hence, perhaps, it should be used as a routine examination to help assess the severity of such a special subtype of $\mathrm{MH}$.

Good preoperative visual acuity and no severe RPE and choroid damage might suggest better postoperative visual acuity. Postoperative BCVA was improved in all patients and was only significantly correlated with the preoperative BCVA, not with preoperative $\mathrm{MD}$ or $\mathrm{BD}$ of the MH. Similarly, in a study by Qi, postoperative BCVA was not correlated with the preoperative size of the $\mathrm{MH}$ [5]. Further, the mean BCVA of the D-RPE group was significantly worse than that of the ND-RPE group both preoperatively and postoperatively. And both pre- and post-operative BCVA was significantly correlated with RPE destruction. Thus, we inferred that RPE and choroidal damage may play an important role in the pathophysiological mechanism of laser-induced $\mathrm{MH}$ and may also account for the unsatisfactory recovery of macular structure and BCVA after vitrectomy.

There are some limitations in this study. For example, it's a retrospective study and the number of cases is small. However, this study enriches the understanding of surgical outcomes of macular hole caused by laser injury.

In summary, this study supported that laser-induced macular hole could be treated by vitrectomy combined with ILM peeling and gas tamponade. Postoperative BCVA may be correlated with preoperative BCVA. Finally, If RPE/choroid is involved in laser damage in addition to the outer retinal layer, this may indicate poor visual prognosis.

\section{Acknowledgments}

The authors thank Xin Huang, Qing Chang (Eye \& ENT Hospital, Fudan University) for their contributions to data collection.

\section{Authors' contributions}

XW and TZ contributed equally to this work. RJ and GZX conceived and designed the work. XW and TZ collected and analyzed the data. XW and TZ wrote the manuscript. All authors commented on previous versions of the manuscript and approved the final manuscript.

\section{Funding}

This work was supported by the Youth Project of the National Natural Science Fund (Grant No. 81500723, 81700861), the National Natural Science Foundation of China (Grant Nos.81570854) and Study on comprehensive prevention and control of common eye diseases in xuhui district (XHLHGG201807).

\section{Availability of data and materials}

The datasets used and/or analysed during the current study available from the corresponding author on reasonable request.

\section{Declarations}

\section{Ethics approval and consent to participate}

This study was approved by the Medical Ethical Committee of the Eye and ENT Hospital of Fudan University. Each patient or his/her legal representative signed the informed consent under the tenets of the Helsinki Declaration.

Consent for publication

Not applicable.

\section{Competing interests}

The authors declare that they have no conflict of interest.

\section{Author details}

${ }^{1}$ Eye Institute and Department of Ophthalmology Vision Sciences, Eye \& ENT Hospital, Fudan University, 83 Fenyang Road, Shanghai 200031, China. ${ }^{2}$ NHC Key Laboratory of Myopia (Fudan University); Key Laboratory of Myopia, Chinese Academy of Medical Sciences, Shanghai 200031, China. ${ }^{3}$ Shanghai Key Laboratory of Visual Impairment and Restoration, Shanghai 200031, China.

Received: 26 October 2020 Accepted: 1 March 2021

Published online: 14 March 2021

\section{References}

1. Petrou P, Patwary S, Banerjee PJ, Kirkby GR. Bilateral macular hole from a handheld laser pointer. Lancet. 2014:383(9930):1780.

2. Androudi S, Papageorgiou E. Macular hole from a laser pointer. $N$ Engl Med. 2018:378(25):2420-0.

3. Shuai Y, Chen X, Fang W, Li J, Ge W, Yuan S, et al. Focal choroidal excavation and a traumatic macular hole secondary to accidental Qswitched Nd:YAG laser. Photodiagn Photodyn Ther. 2017;19:345-7.

4. Alsulaiman SM, Alrushood AA, Almasaud J, Alkharashi AS, Alzahrani Y, Abboud EB, et al. Full-thickness macular hole secondary to High-power handheld blue laser: natural history and Management outcomes. Am J Ophthalmol. 2015;160(1):107-13.

5. Qi Y, Wang Y, You Q, Tsai F, Liu W. Surgical treatment and optical coherence tomographic evaluation for accidental laser-induced fullthickness macular holes. Eye (Lond). 2017;31(7):1078-84.

6. Botsford BW, Williams AM, Martel JN. High-powered blue-light laser-induced MACULOPATHY in an adolescent: multi-modal imaging, evolution, and MANAGEMENT. Retinal Cases Brief Rep. 2020;00:1-4.

7. Yang YH, Chung YT, Kim BK, Moon JH, Mun SJ. Inverted internal limiting membrane flap technique and an autologous platelet concentrate to treat an Nd:YAG laser-induced macular hole. A case report. Medicine. 2019;98(47): e18185.

8. Michalewska Z, Michalewski J, Adelman RA, Nawrocki J. Inverted internal limiting membrane flap technique for large macular holes. Ophthalmology. 2010:117(10):2018-25.

9. Barkana Y, Belkin M. Laser eye injuries. Surv Ophthalmol. 2000;44(6):459-78. 
10. Mainster MA. Assessment of alleged retinal laser injuries. Arch Ophthalmol. 2004;122(8):1210-7.

11. Alsulaiman SM, Alrushood AA, Almasaud J, Alzaaidi S, Alzahrani Y, Arevalo $\mathrm{JF}$, et al. High-power handheld blue laser-induced Maculopathy. Ophthalmology. 2014;121(2):566-72.

12. Raoof N, Bradley P, Theodorou M, Moore AT, Michaelides M. The new pretender: a large UK case series of retinal injuries in children secondary to handheld lasers. Am J Ophthalmol. 2016;171:88-94.

13. Wyrsch $S$, Baenninger PB, Schmid MK. Retinal injuries from a handheld laser pointer. N Engl J Med. 2010;363(11):1089-91.

14. Raoof N, Chan TK, Rogers NK, Abdullah W, Haq I, Kelly SP, et al. 'Toy' laser macular burns in children. Eye (Lond). 2014;28(2):231-4.

15. Sou R, Kusaka S, Ohji M, Gomi F, Ikuno Y, Tano Y. Optical coherence tomographic evaluation of a surgically treated traumatic macular hole secondary to Nd:YAG laser injury. Am J Ophthalmol. 2003:135(4):537-9.

16. Lee GD, Baumal CR, Lally D, Pitcher JD, Vander J, Duker JS. Retinal injury after inadvertent handheld laser exposure. Retina. 2014;34(12):2388-96.

17. Tran K, Wang D, Scharf J, Sadda S, Sarraf D. Inner choroidal ischaemia and CNV due to handheld laser-induced maculopathy: a case report and review. Eye. 2020;34(11):1958-65.

\section{Publisher's Note}

Springer Nature remains neutral with regard to jurisdictional claims in published maps and institutional affiliations.

Ready to submit your research? Choose BMC and benefit from:

- fast, convenient online submission

- thorough peer review by experienced researchers in your field

- rapid publication on acceptance

- support for research data, including large and complex data types

- gold Open Access which fosters wider collaboration and increased citations

- maximum visibility for your research: over $100 \mathrm{M}$ website views per year

At BMC, research is always in progress.

Learn more biomedcentral.com/submissions 